\title{
Predicting effects of future development on a territorial forest songbird: methodology matters
}

\author{
Michelle L. Brown • Therese M. Donovan • Ruth M. Mickey • Gregory S. Warrington • \\ W. Scott Schwenk - David M. Theobald
}

Received: 30 October 2016/Accepted: 14 October 2017/Published online: 8 November 2017

(C) The Author(s) 2017. This article is an open access publication

\begin{abstract}
Context Projected increases in human population size are expected to increase forest loss and fragmentation in the next century at the expense of forestdwelling species.

Objectives We estimated landscape carrying capacity $\left(N_{\mathrm{k}}\right)$ for Ovenbirds in urban, suburban, exurban, and rural areas for the years 2000 and 2050, and compared changes in $N_{\mathrm{k}}$ with changes in occupancy probability.
\end{abstract}

Electronic supplementary material The online version of this article (doi:10.1007/s10980-017-0586-8) contains supplementary material, which is available to authorized users.

\section{L. Brown $(\square) \cdot$ W. S. Schwenk}

Vermont Cooperative Fish and Wildlife Research Unit, Rubenstein School of Environment and Natural

Resources, University of Vermont, Burlington, VT 05405 ,

USA

e-mail: Michelle.L.Brown@uvm.edu;

michelle_brown@tnc.org

T. M. Donovan

U. S. Geological Survey, Vermont Cooperative Fish and Wildlife Research Unit, Rubenstein School of

Environment and Natural Resources, University of

Vermont, Burlington, VT 05405, USA

R. M. Mickey · G. S. Warrington

Department of Mathematics and Statistics, University of Vermont, Burlington, VT 05405, USA
Methods Maximum clique analysis, a branch of mathematical graph theory, was used to estimate landscape carrying capacity, the maximum potential number of territories a given landscape is capable of supporting $\left(N_{\mathrm{k}}\right)$. We used occupancy probability maps as inputs for calculating Ovenbird $N_{\mathrm{k}}$ in the northeastern USA and a spatially explicit growth model to forecast future development patterns in 2050. We compared occupancy probability with estimates of $N_{\mathrm{k}}$ for urban, suburban, exurban, and rural areas for the years 2000 and 2050 .

Results In response to human population growth and development, Ovenbird $N_{\mathrm{k}}$ was predicted to decrease

D. M. Theobald

Department of Fish, Wildlife, and Conservation Biology,

Colorado State University, Fort Collins, CO 80523, USA

Present Address:

M. L. Brown

The Nature Conservancy, PO Box 65, Keene Valley,

NY 12943, USA

Present Address:

W. S. Schwenk

North Atlantic Landscape Conservation Cooperative, Hadley, MA 01035, USA

Present Address:

D. M. Theobald

Conservation Science Partners, Inc, Fort Collins, CO 80524, USA 
$23 \%$ in urban landscapes, $28 \%$ in suburban landscapes, $43 \%$ in exurban landscapes, and $20 \%$ in rural landscapes. These decreases far exceeded decreases in mean occupancy probabilities that ranged between 2 and 5\% across the same development categories. Thus, small decreases in occupancy probability between 2000 and 2050 translated to much larger decreases in $N_{\mathrm{k}}$.

Conclusions For the first time, our study compares occupancy probability with a species population metric, $N_{\mathrm{k}}$, to assess the impact of future development. Maximum clique analysis is a tool that can be used to estimate $N_{\mathrm{k}}$ and inform landscape management and communication with stakeholders.

Keywords Landscape carrying capacity . Occupancy modeling · Human population growth . Maximum clique · Graph theory · Forest fragmentation · Ovenbird · Northeastern USA

\section{Introduction}

For the first time in over a century, forest cover has peaked and is declining in every northeastern state in the United States (Foster et al. 2010). Several drivers have contributed to this trend, notably human population growth and development (Alig et al. 2004; Tyrrell 2004; Brown et al. 2005; Drummond and Loveland 2010; Lepczyk et al. 2013). According to the U.S. Census Bureau, four million new people are predicted to be added to the northeastern landscape between the years 2000 and 2030 (U.S. Census Bureau 2005), which is expected to continue and intensify forest loss and development (Nowak and Walton 2005; Stein 2005; DeNormandie et al. 2009; Foster et al. 2010; Lepczyk et al. 2013).

The amount of human population growth is one factor that can affect forest loss. The distribution of people and houses on a landscape is a second factor that affects both forest loss and forest fragmentation (Theobald 2003; Radeloff et al. 2005a, b; Theobald 2005; Pidgeon et al. 2007; Bierwagen et al. 2010; Sushinsky et al. 2012). This can translate into disproportionately large effects of development on biodiversity, particularly in low-density residential areas (Hansen et al. 2005; Radeloff et al. 2005b; Theobald 2005). These low-density areas have been described as exurban (Brown et al. 2005; Theobald 2005) or the wildland-urban interface (WUI) (Radeloff et al. 2005b). Exurban areas often contain viable forest habitat for species occupancy, but can be under threat of conversion due to proximity to environmental amenities such as forests, lakes, and protected lands (Rasker and Hansen 2000; Brown et al. 2005; Bierwagen et al. 2010).

In the face of future development and subsequent forest loss and fragmentation, wildlife biologists are pressed to estimate the risk of increased development to wildlife populations-how will species respond? The abundance, distribution, and viability of wildlife populations can be intricately tied to the condition of the landscape mosaic (Forman 1995; Turner et al. 2001; Scott et al. 2002; Haslem and Bennett 2008; Brady et al. 2009; Dover and Settele 2009; Bissonette 2012). However, wildlife managers often cannot manipulate the landscape mosaic on behalf of wildlife. Given these challenges, spatially explicit tools are needed to quantify how individual species' distributions are expected to change in response to increased development. Additionally, metrics are needed that can be easily communicated to wildlife practitioners and decision-makers alike (Burdett 2010; Brown et al. 2014).

One common method used to estimate the distribution of animals is to calculate the probability that a species will occur in the landscape based on spatial covariates. Occupancy models use empirical detection and non-detection data and species' sensitivities to variables such as forest amount, forest arrangement, and percent development to estimate the probability that a species will occur $(\psi)$ (MacKenzie et al. 2006). In a recent paper, Schwenk and Donovan (2011) modeled $\psi$ for over 60 bird species using a singlespecies occupancy modeling framework and several landscape covariates including forest cover, road density, and distance to the nearest edge of a different land cover class. In a second paper, this methodology was expanded to predict $\psi$ in future decades (to the year 2050) for five forest-dependent birds species in the northeastern USA based on projected changes in human housing density, developed lands, forest cover, and distance to the nearest edge of a different land cover class (Brown et al. 2014). The probability of occupancy for each species decreased by as much as $38 \%$ at specific locations within the study area and nearly all towns $(97 \%)$ had projected declines between 
the years 2000 and 2050. However, average declines in occupancy across the study area were minimal, ranging from $0 \%$ (Hairy Woodpecker) to $2 \%$ (Blackthroated Green Warbler, Ovenbird, and Hermit Thrush). These results suggested that distribution patterns of these species might not change considerably in response to future land use change.

An alternative measure that is readily understood by decision makers in assessing responses to future land use change is wildlife population size (Rosenberg and Blancher 2005). Traditional methods for estimating species' populations, including mark-recapture, total counts, and indirect counts, can be effective, but are often too costly or impractical for many species. Maximum clique analysis (MCA), a branch of mathematical graph theory, provides a novel way to estimate the maximum potential population size of a territorial species $\left(N_{\mathrm{k}}\right)$ a landscape is capable of supporting, given its current composition and configuration (Donovan et al. 2012). For example, in the case of territorial songbirds, $N_{\mathrm{k}}$ represents the maximum number of breeding territories a defined landscape can support. Although the actual population size may be less than $N_{\mathrm{k}}$, species' responses to future land use change can be evaluated using $N_{\mathrm{k}}$.

To estimate $N_{\mathrm{k}}$ using maximum clique analysis, consider a mathematical graph that consists of a set of points (called objects) and edges that link the points. Each edge indicates a relationship between its associated pair of points. For example, if a graph represented a social network, points may indicate people, and edges may indicate friendships. Some points have no connections (a loner), some have few connections, and some (connectors, sensu Gladwell 2000) may have many connections. A clique in a graph is a subset of the points in which every pair of points is linked with an edge. Relative to a social network, a clique would correspond to a group of mutual friends. A clique is said to be maximum in a graph if a clique with more points does not exist (e.g., the largest group of mutual friends). In terms of wildlife, points represent potential breeding territories in a landscape, edges are drawn between two points if the two territories can co-exist on the landscape without overlap, and the maximum clique is the maximum number of territories that the landscape can support $\left(N_{\mathrm{k}}\right)$.

In this paper, we use occupancy models as inputs for maximum clique analysis to predict changes in the landscape carrying capacity $\left(N_{\mathrm{k}}\right)$ for a forest-nesting bird as a result of predicted future landscape development. Figure 1 illustrates how to transform an occupancy map into an estimate of $N_{\mathrm{k}}$ with maximum clique analysis under the assumption that probability of occupancy is directly related to habitat suitability (Martin et al. 2010; Donovan et al. 2012). First, an occupancy map has pixel values that range between 0 and 1 (Fig. 1a). In this example, a focal pixel in row 3 , column 3 has an occupancy probability of 0.6 (Fig. 1a). The circle represents a buffered polygon that simulates a territory that encompasses multiple pixels. Second, a moving window analysis is conducted in which the average $\psi$ of the pixels within the territory window is computed. This results in a raster (the "territory capacity raster") in which each pixel provides the average occupancy probability of a hypothetical breeding territory (Fig. 1b). A numeric threshold ("cutoff") is set based on what is considered a suitable territory score for the target species. In Fig. 1b, all pixels that are greater to or equal than a hypothetical cutoff of 0.8 are shaded, indicating that they have sufficient resources in the surrounding cells to support a breeding territory. The two locations that meet the habitat threshold are retained, numbered 1 and 2, and buffered to simulate the placement of pseudo territories on the landscape (Fig. 1c). The pseudo territory locations are converted from spatial locations to points (nodes) in a mathematical graph, and edges are drawn between points that can co-exist without overlapping territorial boundaries (Fig. 1d). In this example, a maximum clique analysis of this graph yields $N_{\mathrm{k}}=2$ because two territories can coexist on the landscape without overlapping territorial boundaries. Figure 1e-h provides a second example, resulting in six potential territories. However, the maximum clique is $N_{\mathrm{k}}=3$ because the landscape is capable of supporting only three territories that do not overlap territorial boundaries. Logically, $N_{\mathrm{k}}$ may be sensitive to both the territory size and to the cutoff selected (Donovan et al. 2012).

The goal of this study was to compare occupancy probability and $N_{\mathrm{k}}$ as quantitative metrics and examine their use in informing conservation and management with respect to projected land use change. We selected a forest-dependent songbird that is sensitive to development and forest fragmentation, the Ovenbird (Seiurus aurocapillus), as a model organism. The objectives of our study were to: (1) Estimate landscape carrying 
(a)

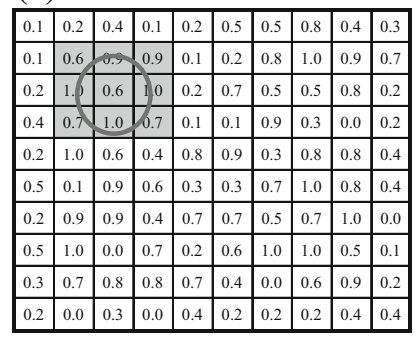

(e)

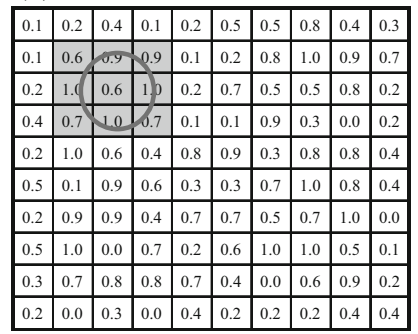

(b)

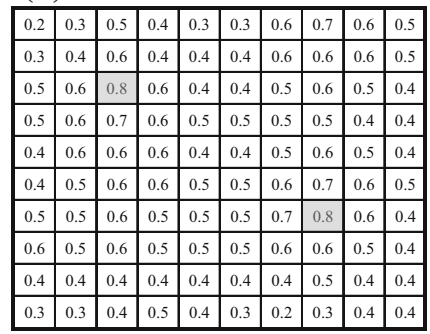

(f)

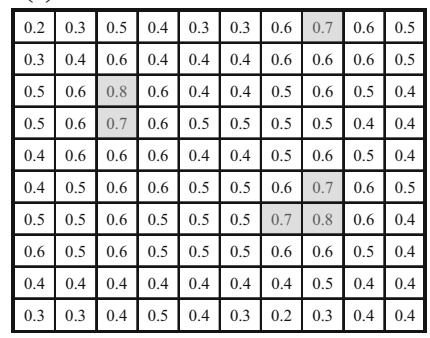

(c)

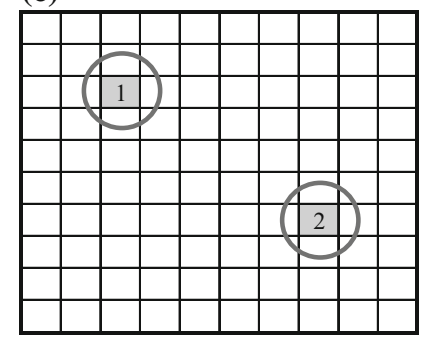

(g)

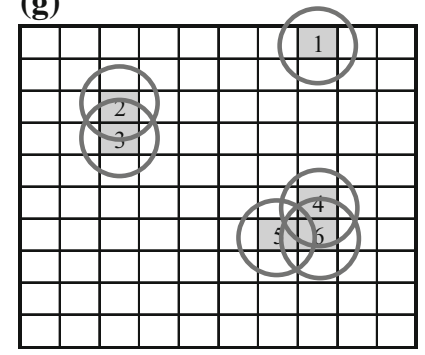

(d)

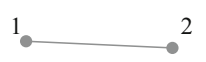

Fig. 1 From Donovan et al. 2012. a Hypothetical occupancy map showing pixel values that range between 0 and 1 . A focal pixel in row 3, column 3 has an occupancy score of 0.6. The circle represents a buffered polygon that simulates a territory; b Hypothetical territory capacity map based on Fig. 1a, in which the pixel score is the average of the focal pixel plus the 8 surrounding cells. All pixels that are $\geq$ to a hypothetical pseudo territory threshold of 0.8 are shaded; $\mathbf{c}$ The two locations that meet the threshold are retained, numbered 1 and 2, and buffered to simulate the placement of pseudo territories on the landscape. In this example, we used circular buffers to simulate pseudo territories of the same size, resulting in a maximum of 2 territories that can co-exist on the landscape without overlap,

capacity $\left(N_{\mathrm{k}}\right)$ for the Ovenbird in four residential housing development classes: urban, suburban, exurban, and rural, for the years 2000 and 2050, and (2) Compare changes in occupancy probability with changes in $N_{\mathrm{k}}$.

\section{Methods}

Study area

The study area was the three-state region of Vermont, New Hampshire, and mainland Massachusetts, USA ( 76,100 square kilometers; Fig. 2). It was approximately $68 \%$ forest, $11 \%$ developed, $9 \%$ agriculture, $6 \%$ wetlands, $4 \%$ open water, $1 \%$ shrubland, and less than $1 \%$ bare rock and grassland according to the 2001 National Land Cover Dataset (NLCD) (Multi- and $N_{\mathrm{k}}=2 ; \mathbf{d}$ The pseudo territory locations are de-spaced and converted to points on a graph, and edges are drawn between points that can co-exist without overlapping boundaries. A maximum clique analysis of this graph yields $N_{\mathrm{k}}=2$; e The same occupancy map as (a) is duplicated for a new analysis; $\mathbf{f ~ A ~}$ new hypothetical territory capacity map is created with a hypothetical pseudo territory threshold of $0.7 ; \mathbf{g}$ The six locations that meet the 0.7 threshold are numbered retained and numbered 1-6; $\mathbf{h}$ The pseudo territory locations are despaced and converted to points on a graph as in (d). The maximum clique of this graph $\left(N_{\mathrm{k}}\right)$ is 3 . The maximum clique $\left(N_{\mathrm{k}}\right)$ can be achieved in 6 ways: Examples include points 1,2 , and 4 and points 1,3 , and 5

Resolution Land Characteristics Consortium 2001). We defined the residential housing development categories (hereafter, "development categories") based on housing unit density thresholds from Theobald (2005): (1) "urban" housing densities are $<0.1$ ha per unit; (2) "suburban" housing densities are between 0.1 and 0.68 ha per unit; (3) "exurban" densities are between 0.68 and 16.18 ha per unit; and (4) "rural" housing densities are $>16.18$ ha per unit (Fig. 2). Approximately 50\% of the landscape was categorized as exurban, $36 \%$ as rural, and $12 \%$ suburban and 3\% urban development categories in the year 2000. Between the years 2000 and 2050, Brown et al. (2014) predicted that roughly half a million new housing units will be added to the landscape in $\mathrm{VT}, \mathrm{NH}$, and MA using a spatially explicit growth model (SERGoM) that operates on $100 \mathrm{~m}^{2}$ pixels (Bierwagen et al. 2010). Developed 
Fig. 2 Study area of Vermont, New Hampshire, and Massachusetts, USA, illustrating four developed land classes in 2000 (urban $=$ pentagon, suburban = triangle, exurban $=$ circle, and rural $=$ square) and two study designs

(white = "Ovenbird" study design and

black = "Random" study design). Sites in the

"Ovenbird" study design contained at least 1

Ovenbird pseudo territory in 2000; sites in the "Random" study design were selected at random. Developed land classes are defined based on the number of housing units per hectare; where urban housing densities are $<0.1$ ha per unit; suburban housing densities are between 0.1 and 0.68 ha per unit; exurban densities are between 0.68 and 16.18 ha per unit; and rural housing densities are $>16.18$ ha per unit

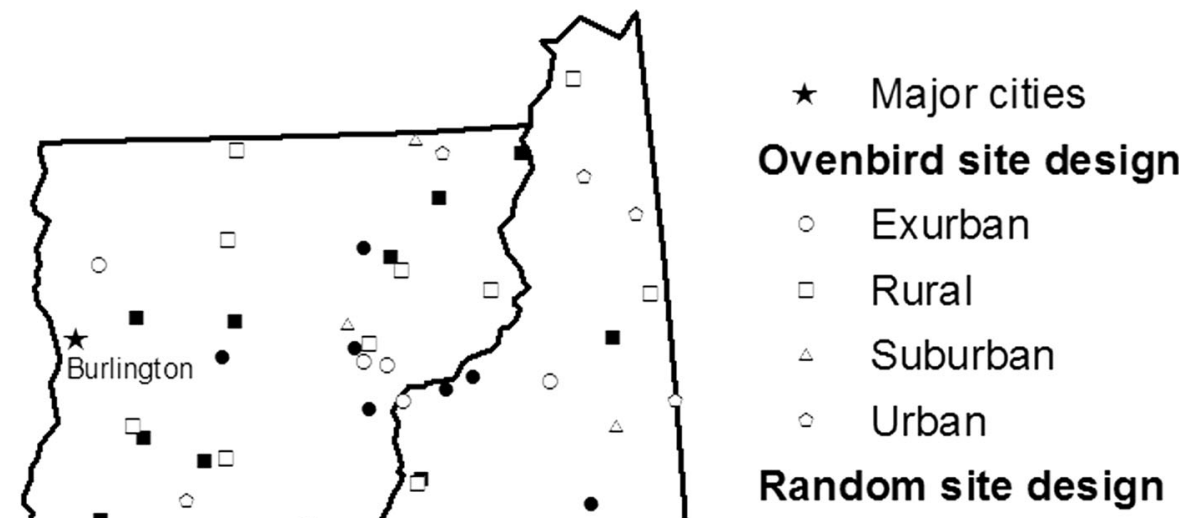

- Exurban

- Rural

- Suburban

- Urban areas (urban, suburban, and exurban) were expected to rise in roughly the same proportion as rural areas were predicted to decline, and the forecasted configuration of development followed similar predicted development patterns in other parts of the United States (Theobald 2005). We chose a 50 year time horizon for forecasting future development patterns because it is reasonable for long-term planning 
(Agarwal 2002; Lepczyk et al. 2013; Thompson et al. 2014).

\section{Target species}

The Ovenbird was selected for analysis based on its habitat preferences and sensitivities to forest loss and fragmentation. This neotropical migrant songbird breeds throughout eastern North American forests. Ovenbirds nest in mature deciduous and mixed forests and are known to prefer large blocks of continuous forests with structural diversity and high canopy closure (60-90\%) (McGowan and Corwin 2008). Ovenbirds are negatively impacted by fragmentation, where nesting success declines as the percentage of forest in the landscape decreases (Robinson et al. 1995) and as the distance to edge decreases (Ortega and Capen 1999). Ovenbirds respond negatively to forest roads, power lines, and chronic noise (Ortega and Capen 1999; Porneluzi 2011). As territorial breeders, Ovenbirds are a good target species for calculating $N_{\mathrm{k}}$ through time.

We used Ovenbird occupancy probability maps developed by Brown et al. (2014) as inputs for the MCA analyses. The maps were derived from singleseason occupancy models (MacKenzie et al. 2006) (described fully in Schwenk and Donovan (2011)) for singing male Ovenbirds across the study area for the years 2000 and 2050. Supplementary Table 1 shows the model-averaged coefficients obtained through the occupancy model analysis (Schwenk and Donovan 2011); goodness-of-fit confirmed the model described the observed field data (MacKenzie and Bailey 2004). The strongest predictor of Ovenbird occupancy was forest cover (percent forest cover within $1 \mathrm{~km}$ ), a variable that often declines in response to increases in human population growth.

\section{Study design}

Maximum clique analysis (MCA) is a computingintensive endeavor; as such, we estimated changes in $N_{\mathrm{k}}$ for 160 study sites that were roughly 40 ha in size and at least $2000 \mathrm{~m}$ apart to ensure spatial independence. The 160 sites were selected via two alternative experimental designs. In the "Random" design, 80 sites were selected with stratified random sampling ( $n=20$ sites in each development category: urban, suburban, exurban, or rural). In the "Ovenbird" design, sites were similarly selected at random, but under the condition that at least 1 Ovenbird pseudoterritory was present in the year 2000. The second design was necessary because many randomly selected sites in urban and suburban development categories did not contain viable Ovenbird habitat $\left(N_{\mathrm{k}}=0\right)$, and thus would not be expected to change over time.

To select study sites, we assigned each $100 \mathrm{~m}^{2}$ pixel in the study area to one of four development categories (urban, suburban, exurban, or rural) based on housing density in the year 2000 (Theobald 2005). Open water and protected lands were not classified with a development category (Bierwagen et al. 2010) because no future development will occur on those pixels. Next, we conducted a moving window analysis to identify the overall development category associated with the majority of pixels contained within a $357 \mathrm{~m}$ radius of the focal pixel $(\sim 40 \mathrm{ha})$, now referred to as a potential study site. Eighty sites were randomly selected from the potential study sites for both the "Random" design and the "Ovenbird" design, where at least 1 pseudo territory was present in the year 2000. By restricting our analyses to sample sites, our sampling design did not permit us to estimate $N_{\mathrm{k}}$ across the entire study area, but was sufficient to understand how changes in the future will likely result in each of the development categories.

\section{Estimating Ovenbird $N_{\mathrm{k}}$ using maximum clique} analysis

We estimated $N_{\mathrm{k}}$ for each study site in the year 2000 and 2050 with maximum clique analysis, and evaluated the sensitivity of $N_{\mathrm{k}}$ to three alternative Ovenbird territory sizes and three alternative territory cutoff values, described below. The general approach for each site is described fully in Donovan et al. (2012) and follows the steps outlined in Fig. 1. Briefly, a $30 \mathrm{~m}$ resolution occupancy map (year 2000 or 2050 from Brown et al. 2014) was the starting input (Fig. 1a), clipped to the 40 ha study sites. Given the pixel size of an occupancy map was smaller than the territory size of an Ovenbird, the first step was to convert the occupancy map so that pixel scores depicted the territory capacity (Compton et al. 2006), achieved by assuming each pixel in the occupancy raster was the center of a pseudo territory, and computing a score so that the pixel value reflected 
the average suitability of the pixel itself plus the surrounding area within territorial boundaries (e.g., Fig. 1b). We created three such "territory capacity" rasters based on alternative Ovenbird territory sizes: small $(90 \times 90 \mathrm{~m}$ territories $=0.81$ ha $)$, medium $(150$ $\times \quad 150 \mathrm{~m}=2.25 \mathrm{ha})$, and large $(270 \times$ $270 \mathrm{~m}=7.29 \mathrm{ha}$ ), covering the extent of Ovenbird territory sizes across the Northeast U.S. (Porneluzi 2011). Second, for a given territory capacity raster, pixel locations not meeting a minimum territory cutoff were eliminated (e.g., Fig. 1c). For each territory capacity raster, we considered three cutoff values: $0.71,0.77$, and 0.83 . For any given cutoff value, we assumed those locations below the cutoff value did not contain sufficient resources to constitute an Ovenbird pseudo territory. The cutoff 0.77 was determined by calculating the median territory capacity scores from the occupancy maps in locations where Ovenbirds were known to occur with certainty in Vermont based on singing male surveys and an average home range size of 1.89 hectares (Schwenk and Donovan 2011). Third, for each territory capacity map and cutoff combination, each cell that met the cutoff criteria for a pseudo territory was assigned a unique number within each sample site. These represented points in a mathematical graph and potential Ovenbird territories (e.g., Fig. 1c, d). Two points were linked by an edge (i.e., made adjacent) if the corresponding locations could support both pseudo territories without overlapping or violating territory boundaries (e.g., Fig. 1d). Finally, we used the program Cliquer (Niskanen 2003) to find the size of a maximum clique.

In total, 960 maximum clique analyses were run (2 experimental study designs $\times 80$ sites $\times 3$ territory sizes $\times 3$ cutoffs $\times 2$ time periods). For each study design, territory size, and cutoff combination $(n=18$ analyses), a linear mixed model was used to model maximum clique size as a function of two fixed factors, development category (urban, suburban, exurban, rural) and year $(2000,2050)$ and their interaction, and one random factor (site). All computations were done in (R Core Team 2017) with the lme function in the package, nlme (Pinheiro 2017). Residual plots were used to evaluate if the assumptions of the lme model were met.
Comparing changes in occupancy probability with changes in $N_{\mathrm{k}}$

We calculated the average occupancy probability for three territory sizes for each sample site for the years 2000 and 2050. For each study design and territory size ( $n=6$ analyses), a linear mixed model was used to model the average territory occupancy score as a function of two fixed factors, development category (urban, suburban, exurban, rural) and year (2000, 2050) and their interaction, along with one random factor (site). All computations were done in (R Core Team 2017) with the lme function in the package, nlme (Pinheiro 2017). Residual plots were used to evaluate if the assumptions of the lme model were met.

\section{Results}

Estimating Ovenbird $N_{\mathrm{k}}$ using maximum clique analysis

Given a 40 hectare study site, $N_{\mathrm{k}}$ was greatest in rural development categories, where the largest $N_{\mathrm{k}}$ observed was 33, 19, and 12 Ovenbird territories for small, medium, and large sized territories, respectively, providing a benchmark for comparison. For all 18 assessments (study design $\times$ territory size $\times$ cutoff combinations), mean $N_{\mathrm{k}}$ estimates varied with development category and year (Table 1), with effect sizes depicted in Fig. 3. Residual plots suggested that the assumptions of the lme model were essentially met. In general, mean $N_{\mathrm{k}}$ decreased overall as both territory cutoff and territory size increased (Fig. 3). These patterns can be explained through graph theory; the cutoff selected for clique analysis alters the number of points (potential pseudo territories) in a graph, and the territory size alters the number of edges in a graph.

In the "Random" study design in which sites were randomly selected within each development category, the mean value of $N_{\mathrm{k}}$ over the study sites was 0 or close to 0 in suburban and urban categories regardless of the cutoff or territory size (Fig. 3, row 2). This is because these development categories often do not contain sufficient Ovenbird habitat due to highly fragmented and low levels of forest cover (Porneluzi 2011). For exurban and rural development categories in the "Random" study design, $N_{\mathrm{k}}$ decreased from the year 2000 to the year 2050, with larger declines in smaller 
Table 1 Results of linear mixed model analysis by experiment design, territory size, and cutoff, modeling the effects of development category and year on $N_{\mathrm{k}}$

\begin{tabular}{|c|c|c|c|c|c|c|}
\hline \multirow[t]{2}{*}{ Study design } & \multirow[t]{2}{*}{ Territory size } & \multicolumn{5}{|c|}{ Parameter } \\
\hline & & Cutoff & Intercept & Development & Year & Dev $\times$ year \\
\hline \multirow[t]{9}{*}{ Ovenbird } & \multirow[t]{3}{*}{ Small } & 0.71 & $588.63(<0.001)$ & $9.01(<0.001)$ & $43(<0.001)$ & $5.24(<0.01)$ \\
\hline & & 0.77 & $200.64(<0.001)$ & $11.57(<0.001)$ & $48.44(<0.001)$ & $1.61(\mathrm{~ns})$ \\
\hline & & 0.83 & $27.57(<0.001)$ & $7.93(<0.001)$ & $11.2(<0.01)$ & $2.61(\mathrm{~ns})$ \\
\hline & \multirow[t]{3}{*}{ Medium } & 0.71 & $554.39(<0.001)$ & $11.88(<0.001)$ & $37.59(<0.001)$ & $4.44(<0.01)$ \\
\hline & & 0.77 & $195.35(<0.001)$ & $11.87(<0.001)$ & $44.8(<0.001)$ & $1.37(\mathrm{~ns})$ \\
\hline & & 0.83 & $28.71(<0.001)$ & $8.46(<0.001)$ & $11.23(<0.01)$ & 3.24 (ns) \\
\hline & \multirow[t]{3}{*}{ Large } & 0.71 & $512.45(<0.001)$ & $11.01(<0.001)$ & $39.38(<0.001)$ & $4.39(<0.01)$ \\
\hline & & 0.77 & $192.54(<0.001)$ & $13.02(<0.001)$ & $41.33(<0.001)$ & $1.31(\mathrm{~ns})$ \\
\hline & & 0.83 & $26.76(<0.001)$ & $7.36(<0.001)$ & $12.01(<0.001)$ & $3.35(\mathrm{~ns})$ \\
\hline \multirow[t]{9}{*}{ Random } & \multirow[t]{3}{*}{ Small } & 0.71 & $126.39(<0.001)$ & $44.55(<0.001)$ & $12.03(<0.001)$ & $2.97(\mathrm{~ns})$ \\
\hline & & 0.77 & $44.23(<0.001)$ & $16.99(<0.001)$ & $14.93(<0.001)$ & $4.54(<0.01)$ \\
\hline & & 0.83 & $10.46(<0.01)$ & $8.37(<0.001)$ & $6.08(\mathrm{~ns})$ & $3.26(\mathrm{~ns})$ \\
\hline & \multirow[t]{3}{*}{ Medium } & 0.71 & $120.6(<0.001)$ & $42.7(<0.001)$ & $8.07(<0.01)$ & $2.31(\mathrm{~ns})$ \\
\hline & & 0.77 & $45.13(<0.001)$ & $17.6(<0.001)$ & $14.85(<0.001)$ & $4.59(<0.01)$ \\
\hline & & 0.83 & $10.24(<0.01)$ & $8.51(<0.001)$ & $6.46(\mathrm{~ns})$ & $3.5(\mathrm{~ns})$ \\
\hline & \multirow[t]{3}{*}{ Large } & 0.71 & $108.4(<0.001)$ & $38.81(<0.001)$ & $9.32(<0.01)$ & $2.63(\mathrm{~ns})$ \\
\hline & & 0.77 & $43.83(<0.001)$ & $16.98(<0.001)$ & $10.85(<0.01)$ & $3.2(\mathrm{~ns})$ \\
\hline & & 0.83 & $9.98(<0.01)$ & $8.59(<0.001)$ & $5.64(\mathrm{~ns})$ & 3.35 (ns) \\
\hline
\end{tabular}

F statistics are provided for four effects, with $p$ value in parentheses

territory sizes. The number of territories in exurban habitat declined the steepest in the lowest territory cutoff (0.71), whereas the number of territories in rural habitat declined the steepest in the highest territory cutoff (0.83). For example, for medium sized territories with a territory cutoff of 0.71 (Fig. 3, row 2, column 1), exurban development categories $N_{\mathrm{k}}$ decreased from 8.45 to 7.25 (absolute change $=-1.2$; relative change $=-14.2 \%$ ), while in rural development categories $N_{\mathrm{k}}$ decreased from 13.3 to 13.15 (absolute change $=-0.15$; relative change $=-1.1 \%)$.

These same general patterns held for the "Ovenbird" study design, in which study sites were randomly selected from each development category under the condition that at least 1 Ovenbird pseudo territory was present on the site in the year 2000 (Fig. 3, row 1). This bias in site selection produced estimates of mean $N_{\mathrm{k}}$ that were higher than the "Random" design and resulted in $N_{\mathrm{k}}$ estimates for urban and suburban sites that were on par with exurban areas. For example, for medium sized territories and a territory cutoff of 0.71 (Fig. 3, row 1, column 1), mean $N_{k}$ decreased from 16.15 to 16.05 (absolute change $=-0.1, \quad$ relative change $=-0.6 \%)$, 11.55 to 8.55 (absolute change $=-3$; relative change $=-26.0 \%$ ), $\quad 9.65$ to $7.4 \quad$ (absolute change $=-2.25$; relative change $=-23.3 \%$ ), and 11.45 to 9.65 (absolute change $=-1.8$; relative change $=-15.7 \%$ ) in rural, exurban, suburban, and urban categories, respectively. The $N_{\mathrm{k}}$ results for the highest territory cutoff were similar in the "Ovenbird" and "Random" study designs across all development categories (Fig. 3, rows 1 and 2, column 3).

Comparing changes in occupancy probability with changes in $N_{\mathrm{k}}$

For all 6 assessments (study design $\times$ territory size combinations), mean territorial occupancy scores varied with development category and year (Table 2), with effect sizes depicted in Fig. 4. Residual plots suggested that the assumptions of the lme model were essentially met. Average territory occupancy score 


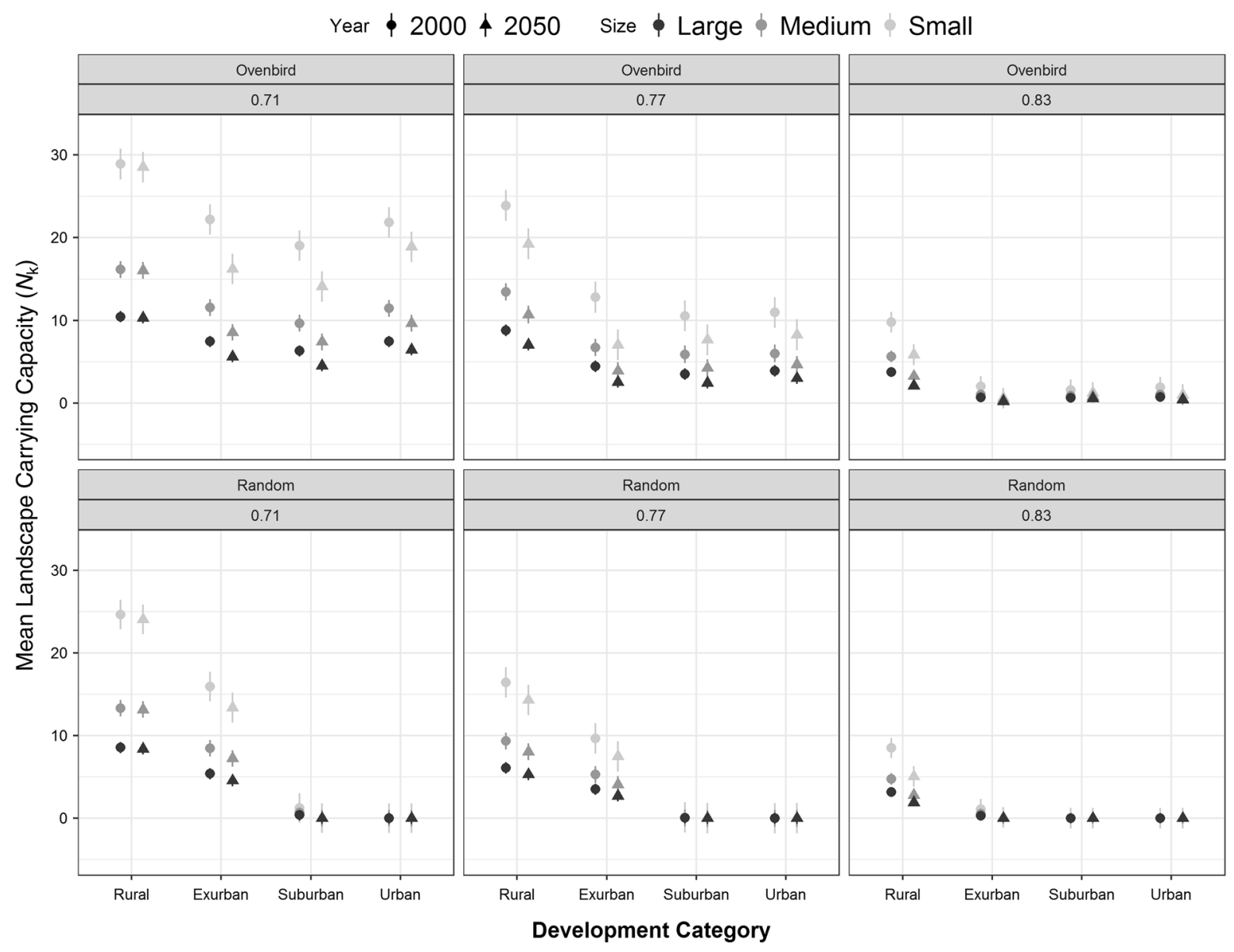

Fig. 3 Changes in mean landscape carrying capacity $\left(N_{\mathrm{k}}\right) \pm 1$ SE between the years 2000 (circles) and 2050 (triangles) in four developed land classes: urban, suburban, exurban, and rural in Vermont, New Hampshire, and Massachusetts, USA. The top row provides results for the "Ovenbird" study design, in which all study sites contained at least 1 Ovenbird pseudo territory in
2000; the bottom row provides results for the "Random" study design in which sites were selected at random. Columns depict results for three cutoff values $(0.71,0.77$, and 0.83$)$. Results are depicted for small (0.81 ha; light gray), medium (2.25 ha; gray), and large (7.29 ha; black) Ovenbird territory sizes

Table 2 Results of linear mixed model analysis by experiment design and territory size, modeling the effects of development category and year on $N_{\mathrm{k}}$

\begin{tabular}{llllll}
\hline Study design & Territory size & Parameter & & \\
\cline { 3 - 6 } & & Intercept & Development & Year & Dev $\times$ year \\
\hline Ovenbird & Small & $3048.46(<0.001)$ & $7.05(<0.001)$ & $62.39(<0.001)$ & $1.16(\mathrm{~ns})$ \\
& Medium & $2881.55(<0.001)$ & $7.61(<0.001)$ & $62.41(<0.001)$ & $1.13(\mathrm{~ns})$ \\
& Large & $2818.77(<0.001)$ & $7.92(<0.001)$ & $62.46(<0.001)$ & $1.13(\mathrm{~ns})$ \\
Random & Small & $370.25(<0.001)$ & $66.96(<0.001)$ & $40.63(<0.001)$ & $3.29(<0.05)$ \\
& Medium & $362.76(<0.001)$ & $67.14(<0.001)$ & $40.55(<0.001)$ & $3.27(<0.05)$ \\
& Large & $360.38(<0.001)$ & $67.39(<0.001)$ & $40.78(<0.001)$ & $3.26(<0.05)$ \\
\hline
\end{tabular}

F statistics are provided for four effects, with $p$ value in parentheses 


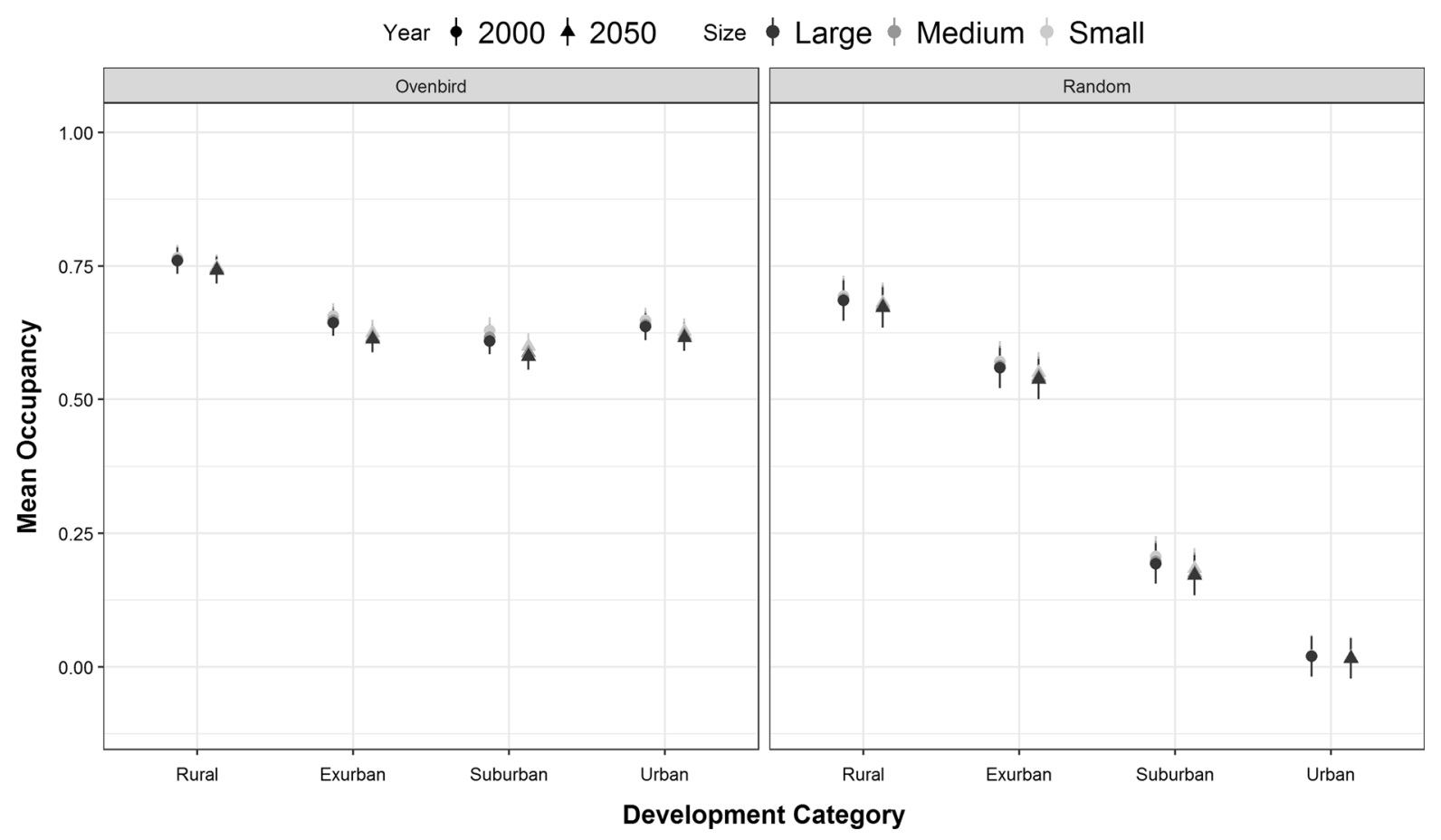

Fig. 4 Changes in mean territory occupancy $(\psi) \pm 1$ SE between the years 2000 (circles) and 2050 (triangles) in four developed land classes: urban, suburban, exurban, and rural in Vermont, New Hampshire, and Massachusetts, USA. The left panel provides results for the "Ovenbird" study design, in which

declined slightly from the year 2000 to the year 2050, but territory size had little impact on this pattern (Fig. 4). In the "Random" design, mean territorial occupancy varied predictably with development category, with rural categories having the greatest territorial occupancy scores and urban having the lowest (Fig. 4, right panel). In the "Ovenbird" study design, average territory occupancy scores were similar for exurban, suburban, and urban development categories, but were lower than the rural category (Fig. 4, left panel). Declines in average occupancy territory scores were $\sim 0.025$, with slightly greater declines in non-rural development categories. For example, in the "Ovenbird" design with medium territory sizes, the absolute decline in average territorial occupancy was $-0.018,-0.031,-0.029$, and -0.020 , for rural, exurban, suburban, and urban development categories, respectively.

We compared the absolute and relative changes between years for the two different metrics (Fig. 5), where relative change was the absolute change divided by the year 2000 metric. In these analyses, we all study sites contained at least 1 Ovenbird pseudo territory in 2000; the right panel provides results for the "Random" study design in which sites were selected at random. Results are depicted for small (0.81 ha; light gray), medium (2.25 ha; gray), and large (7.29 ha; black) Ovenbird territory sizes

compared declines in occupancy with declines in $N_{\mathrm{k}}$ where the territory cutoff was 0.77 . As previously stated and as would be expected due to their different scales, declines in occupancy were much lower than declines in $N_{\mathrm{k}}$. For example, when territory size was assumed to be small in exurban sites within the "Ovenbird" study design, average territorial occupancy scores declined $\sim 0.03$, which resulted in a decline in $N_{\mathrm{k}}$ by $\sim 6$. This $18 \%$ decline in $N_{\mathrm{k}}$ is biologically relevant for a 40 ha site that was observed to contain, at most, 33 territories.

Absolute declines in territory occupancy averaged $<-0.03$ for the "Ovenbird" design and $<-0.02$ for the "Random" design, with highest declines observed in the exurban category within the "Ovenbird" study design $(\sim-0.03)$, and lowest absolute declines observed the urban category within the "Random" study design ( - 0.004). Absolute declines in both $N_{k}$ and territorial occupancy in the "Random" design were close to 0 for suburban and urban categories for the simple reason that starting conditions were very low to begin with (Fig. 5, top 


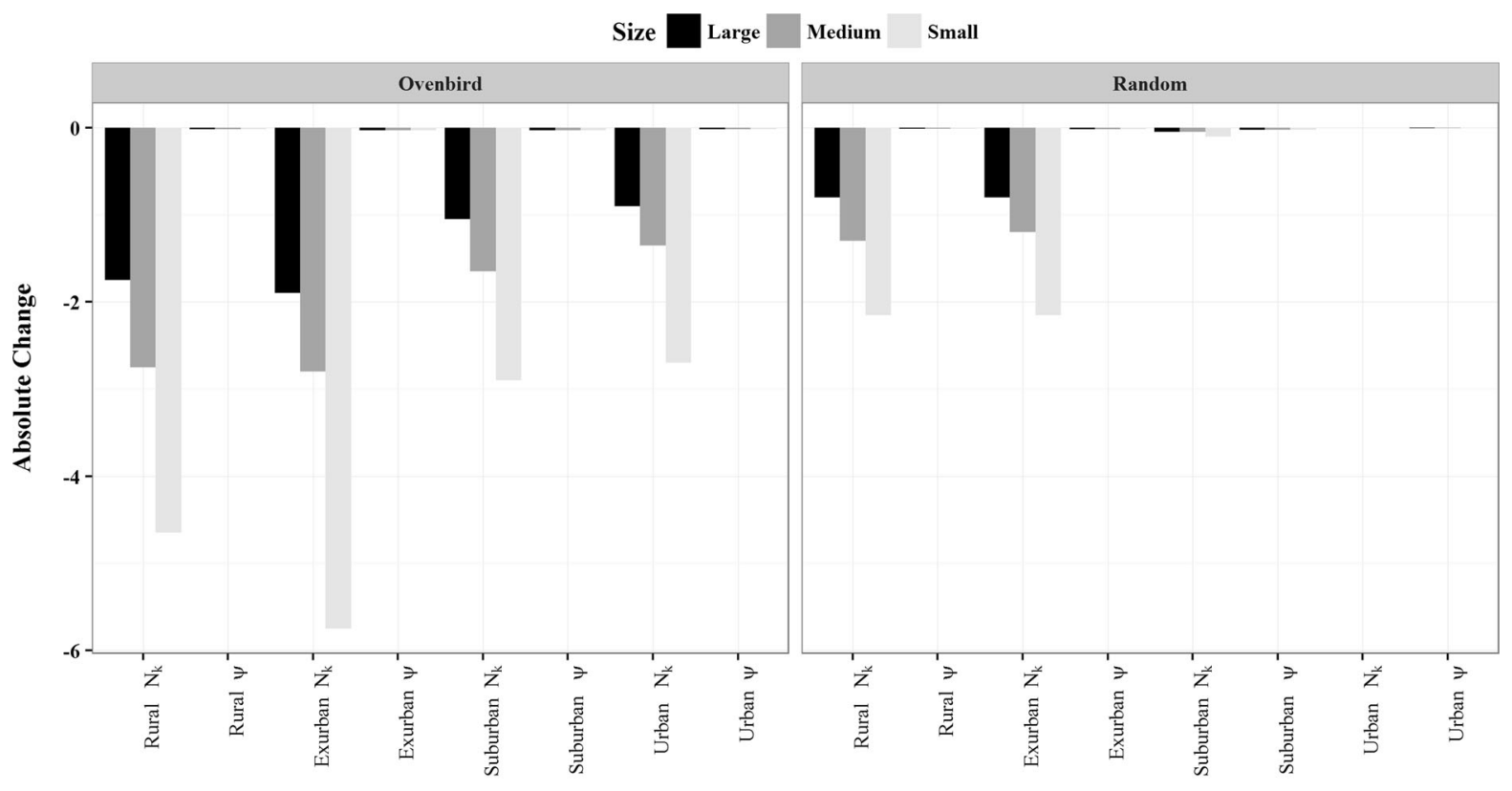

Development Category

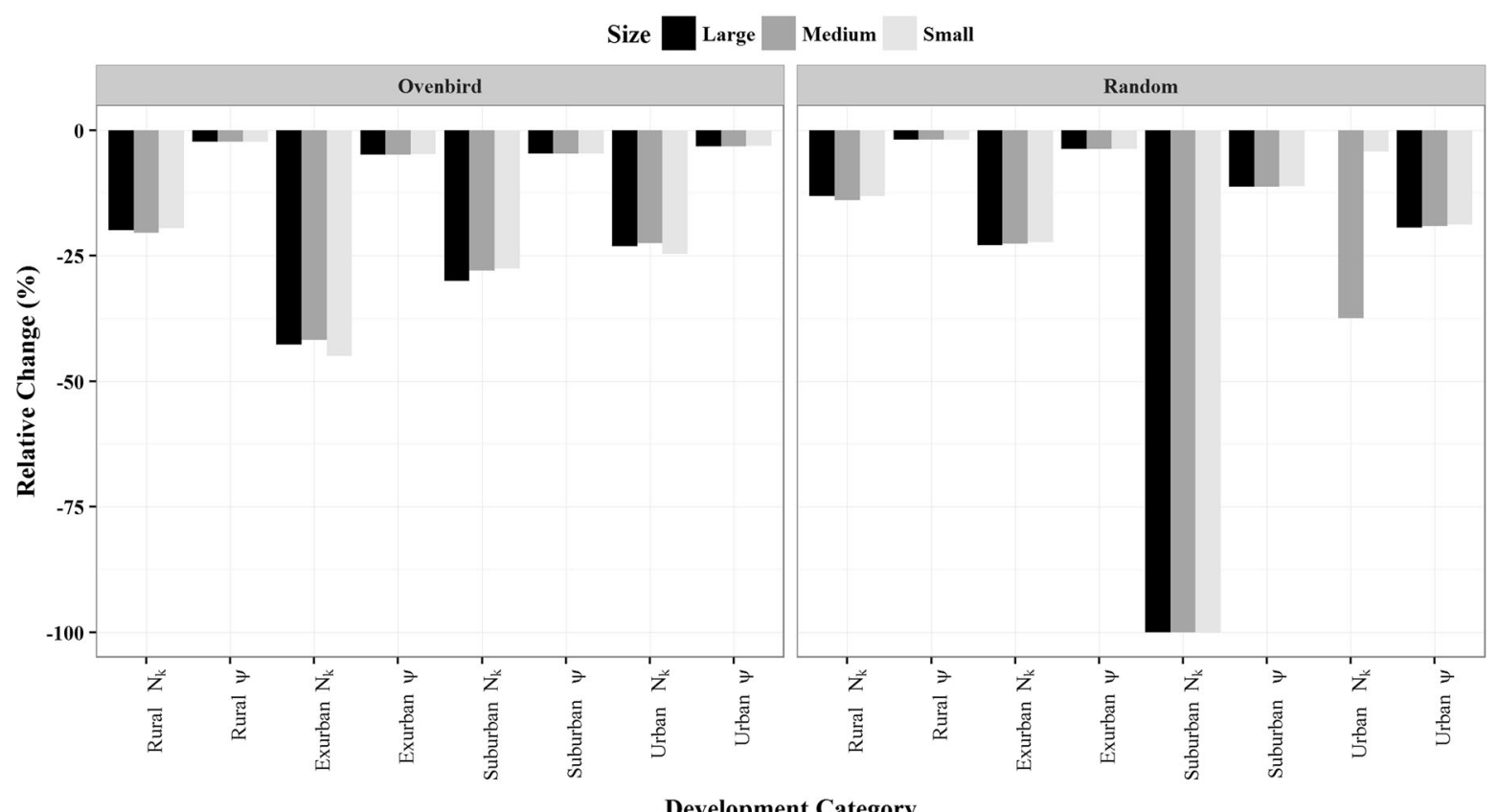

Fig. 5 Absolute change (top) and relative change (bottom) in average $N_{\mathrm{k}}$ and average territory occupancy across the four development categories and three territory sizes for a territory cutoff value of 0.77 . Absolute change is the absolute difference in a metric from 2000 to 2050 . Relative change is the absolute

right panel). In this design, absolute declines in $N_{\mathrm{k}}$ were approximately equal in exurban and rural categories, with greater declines $(\sim 2$ territories $)$ change divided by the starting 2000 condition. Relative change is presented as percentages. Results are depicted for small (0.81 ha; light gray), medium (2.25 ha; gray), and large (7.29 ha; black) territory sizes

observed with small territory sizes. In rural sites assumed to be small, a decline of 2 territories represents a $6 \%$ decline in landscape carrying 
capacity, in contrast to an average territorial occupancy decline of $<2 \%$. In the "Ovenbird" design, absolute declines in $N_{k}$ were greater than in the "Random" design and varied predictably with territory size (Fig. 5, top panel). In this study design, $N_{\mathrm{k}}$ declined by $\sim 5$ in rural sites assumed to be small, a $15 \%$ reduction in landscape carrying capacity, as compared to an average territorial occupancy decline of $<2 \%$.

Patterns of relative declines provided alternative views of decline by development category by comparing how each category changed relative to its year 2000 condition (Fig. 5, bottom panel). In terms of relative declines, occupancy declines in the "Random" design were largest in urban and smallest in the rural development categories. In contrast, suburban sites in the "Random" design exhibited the greatest relative decline in $N_{\mathrm{k}}$ (Fig. 5, bottom right panel), followed by urban, exurban, and rural categories, respectively.

\section{Discussion}

Making decisions based on quantitative metrics is challenging, but essential, for managers, town planners, and politicians. Metrics need to be biologically meaningful, easy to understand, and straightforward to communicate (Schiller 2001). Maximum clique analysis is a methodology that can translate occupancy probabilities and other habitat suitability maps to yield species population parameters, particularly for territorial species. Population metrics are of primary interest in conservation and natural resource management to assess progress toward achieving conservation goals and to learn about system responses to management actions. For example, U.S. Fish and Wildlife Joint Venture programs use abundance metrics to quantify habitat objectives and deliver conservation goals (Petrie 2011). Similarly, several state governments have identified research and monitoring needs or goals for improving species abundance data (New York State Department of Environmental Conservation 2015, Vermont Wildlife Action Plan Team 2015). MCA can help with these needs.

In this paper, we demonstrated that small declines in occupancy can result in significant declines in maximum carrying capacity, $N_{\mathrm{k}}$. Why is there such a divergence in occupancy probability and $N_{\mathrm{k}}$ ? For
Ovenbirds, small changes in forest cover can reduce occupancy probability (Schwenk and Donovan 2011; Supplementary Table 1). Between the years 2000 and 2050, some places in the landscape were predicted to lose as much as $32 \%$ forest cover within a $1 \mathrm{~km}$ window (Brown et al. 2014), but the decline in occupancy probability was only predicted to be $2 \%$ on average for the entire study area. The spatial configuration of where occupancy is being reduced is key to interpreting these patterns - the highest declines occur in exurban areas, regardless of territory size. The minor overall change in occupancy probability likely reflects the fact that occupancy probability in intact habitat cells did not change significantly, while some cells in edge habitat declined more precipitously. In contrast, the decline in $N_{\mathrm{k}}$ likely reflects territories that were lost in edge habitats where occupancy probability was near the habitat threshold. As depicted in this study, occupancy modeling results are driven by changes in intact, core habitat suitability, whereas the carrying capacity results are driven by changes in edge habitat suitability.

In maximum clique analysis, when pseudo territories are placed in the landscape, the average occupancy within the pseudo territory is computed. Only those pseudo territories that meet the habitat threshold are retained as points for the clique analysis, and this depends on the amount and configuration of forest cover within the pseudo territory. Occupancy rates often take on a non-linear function of such covariates, in which small changes in forest cover will not significantly change occupancy rates for sites that are on either end of the covariate's scale (e.g., heavily forested and non-forested sites). However, for sites with intermediate covariate values in the year 2000 small changes in forest cover can change the occupancy rate more significantly. In our study, this is exhibited by the steepest absolute declines in occupancy occurring in the intermediate development categories of suburban and exurban areas, as opposed to rural and urban sites. Suburban and exurban development categories are closer to their tipping point (Gladwell 2000).

The spatial pattern of where $N_{\mathrm{k}}$ will decrease in the landscape has consequences for managers and decision-makers as well as wildlife. In the United States, exurban areas have been growing disproportionately in comparison to the other three development classes in recent years both in terms of absolute amount of 
hectares and rates of development (Vermont Forum on Sprawl 1999; Theobald 2001; Brown et al. 2005; Hansen et al. 2005; Radeloff et al. 2005a; Theobald 2005). In our study area, exurban development occupied a large portion of the landscape $(50 \%$ in the year 2000); such areas have lower $N_{\mathrm{k}}$ than rural areas, but significantly higher $N_{\mathrm{k}}$ compared to suburban and urban areas (see Fig. 3 "Random" design), in part because sizable forest patches can exist within exurban development. This category had the greatest absolute decline in occupancy probability as well as the greatest decline in $N_{\mathrm{k}}$ across analyses. The land use change model used in this analysis focused on increasing number of housing units, causing the further fragmentation of wildlife habitat. This is important because this development category, along with suburban, are projected to increase by $1 \%$ while rural categories are projected to decline by $2 \%$. Even though these changes are small, a $1 \%$ increase in exurban development equates to roughly 694 square kilometers across our entire study area.

Ovenbird territories were also predicted to decline in the suburban and urban land classes, but two study designs were needed to highlight the nature of the change. When sites were randomly selected, $N_{\mathrm{k}}$ was close to 0 (Fig. 3). Mean territorial occupancy scores were low in both categories (Fig. 4). Suburban areas experienced a greater decline in absolute occupancy, perhaps because urban areas have reached their buildout capacity and habitat potential. The "Ovenbird" study design was developed to elucidate changes in $N_{\mathrm{k}}$ and occupancy for these two categories, conditional on the fact that Ovenbird habitat could change in the future. As a result of requiring at least 1 viable pseudo territory per sample site, selected study sites in both suburban and urban areas contained relatively high quality habitat, likely biased toward conserved lands surrounded by development. However, a substantial body of research has shown that Ovenbird populations that do occur within these development categories are likely population sinks, characterized by low densities, low pairing success (Gibbs and Faaborg 1990; Bayne and Hobson 2001), and high nest failure and incidence of brood parasitism by the Brown-headed Cowbird (Molothrus ater) (Donovan et al. 1995; Morimoto et al. 2012); see also (Chalfoun et al. 2002). In addition, Ovenbird territory sizes can vary as a result of habitat quality (Smith and Shugart 1987). Consequently, comparing results with large territory sizes in suburban and urban areas with results from medium or small territory sizes from exurban or rural areas may be justified. If so, the differences in $N_{\mathrm{k}}$ between the housing land cover classifications will be even more exaggerated than our results currently show.

It is often difficult to demonstrate the negative effect of incremental land use change, even though cumulative impacts can be detrimental to natural resources and wildlife (Theobald et al. 1997; Conway and Lathrop 2005; Johnson et al. 2005). Therefore, our results suggest three important considerations for decision makers. First, occupancy probability modeling and other habitat suitability approaches are becoming more widespread. While these are rigorous assessments of the likelihood of species occurrences, our results suggest that small incremental changes in these metrics cumulatively result in big changes in $N_{\mathrm{k}}$. Second, $N_{\mathrm{k}}$ provides a bridge between commonly used occupancy or habitat suitability maps with population parameters that are often defined in management objectives. Third, $N_{\mathrm{k}}$ estimates can be applied at multiple scales. At a landscape scale, $N_{\mathrm{k}}$ can potentially strengthen our understanding of metapopulation or source-sink dynamics that are hypothesized to characterize songbird populations (Tittler et al. 2006; With et al. 2006). Local land use decisions, however, often drive landscape changes on the ground. At a local scale, the $N_{\mathrm{k}}$ metric can be used to assess alternative land use change scenarios that might affect species population size. In turn, these local scale decisions affect broader regional population dynamics.

While our clique analysis can provide an estimated maximum abundance of viable territories, it is not a mechanistic approach. We simply develop our estimates based on the habitat quality of the landscape and don't include the mechanisms by which an individual territory may succeed or fail. Alternative approaches have combined nonspatial population growth models with individual-based spatially explicit models, making it possible to incorporate different population drivers (e.g., parasitism) to abundance estimates (Wilsey et al. 2014). Both methods convert habitat suitability into population estimates, but our results are limited to the relative changes of the estimated maximum number of territories a landscape can support. 
We have demonstrated an approach useful for understanding the potential consequences of land use change on territorial species. This method can be easily adapted for other species, and can be used to provide a more holistic ecosystem approach. Common understanding of the trade-offs between human development and species viability is needed to make informed decisions about the future of wildlife populations.

Acknowledgements We are grateful for feedback from Austin Troy, Jed Murdoch, and three anonymous reviewers, who forced us to think carefully about our study design. We thank the field assistants who conducted bird surveys across Vermont in 2003 and 2004. Funding for this research was provided by the Northeastern States Research Cooperative (USDA). Use of trade names or products does not constitute endorsement by the U.S. Government. The Vermont Cooperative Fish and Wildlife Research Unit is jointly supported by the U.S. Geological Survey, University of Vermont, Vermont Department of Fish and Wildlife, and Wildlife Management Institute.

Open Access This article is distributed under the terms of the Creative Commons Attribution 4.0 International License (http:// creativecommons.org/licenses/by/4.0/), which permits unrestricted use, distribution, and reproduction in any medium, provided you give appropriate credit to the original author(s) and the source, provide a link to the Creative Commons license, and indicate if changes were made.

\section{References}

Agarwal C, Green GM, Grove JM, Evans TP, Schweik CM (2002) A review and assessment of land-use change models: Dynamics of space, time, and human choice. UFS Technical Report NE-297 Burlington, VT: U.S. Department of Agriculture Forest Service, Northeastern Forest Research Station

Alig RJ, Kline JD, Lichtenstein M (2004) Urbanization on the US landscape: looking ahead in the 21 st century. Landsc Urban Plann 69:219-234

Bayne EM, Hobson KA (2001) Effects of habitat fragmentation on pairing success of ovenbirds: importance of male age and floater behavior. Auk 118:380-388

Bierwagen BG, Theobald DM, Pyke CR, Choate A, Groth P, Thomas JV, Morefield P (2010) National housing and impervious surface scenarios for integrated climate impact assessments. Proc Natl Acad Sci 107:20887-20892

Bissonette JA (2012) Wildlife and landscape ecology: effects of pattern and scale. Springer, New York

Brady M, McAlpine C, Miller C, Possingham H, Baxter G (2009) Habitat attributes of landscape mosaics along a gradient of matrix development intensity: matrix management matters. Landscape Ecol 24:879-891
Brown ML, Donovan TM, Schwenk WS, Theobald DM (2014) Predicting impacts of future human population growth and development on occupancy rates of forest-dependent birds. Biol Conserv 179:311-320

Brown DG, Johnson KM, Loveland TR, Theobald DM (2005) Rural land-use trends in the conterminous United States, 1950-2000. Ecol Appl 15:1851-1863

Burdett CL, Crooks KR, Theobald DM, Wilson KR, Boydston EE, Lyren LM, Fisher RN, Vickers TW, Morrison SA, Boyce WM (2010) Interfacing models of wildlife habitat and human development to predict the future distribution of puma habitat. Ecosphere. doi:10.1890/ES1810-00005. 00001

Chalfoun AD, Thompson FR III, Ratnaswamy MJ (2002) Nest predators and fragmentation: a review and meta-analysis. Conserv Biol 16:306-318

Compton BW, McGarigal K, Sievert PR (2006) Models of priority conservation sites for spotted turtles (Clemmys guttata), wood turtle (Glyptemys insculpta) and Blanding's turtle (Emydoidea blandingii). Natural Heritage and Endangered Species Program, Massachusetts Division of Fisheries and Wildlife, Westborough

Conway TM, Lathrop RG (2005) Alternative land use regulations and environmental impacts: assessing future land use in an urbanizing watershed. Landsc Urban Plan 71:1-15

DeNormandie J, Corcoran C, Clarke JJ (2009) Losing ground beyond the footprint: patterns of development and their impact on the nature of Massachusetts. Mass Audubon, Lincoln

Donovan TM, Thompson FR III, Faaborg J, Probst J (1995) Reproductive success of migratory birds in habitat sources and sinks. Conserv Biol 9:1380-1395

Donovan TM, Warrington GS, Schwenk WS, Dinitz JH (2012) Estimating landscape carrying capacity through maximum clique analysis. Ecol Appl 22:2265-2276

Dover J, Settele J (2009) The influences of landscape structure on butterfly distribution and movement: a review. J Insect Conserv 13:3-27

Drummond MA, Loveland TR (2010) Land-use pressure and a transition to forest-cover loss in the Eastern United States. Bioscience 60:286-298

Forman RTT (1995) Land mosaics: the ecology of landscape and region. Cambridge University Press, Cambridge

Foster DR, Donahue BM, Kittredge DB, Lambert KF, Hunter ML, Hall BR, Irland LC, Lilieholm RJ, Orwig DA, D'Amato AW, Colburn EA, Thompson JR, Levitt JN, Ellison AM, Keeton WS, Aber JD, Cogbill CV, Driscoll CT, Fahey TJ, Hart CM (2010) Wildlands and woodlands: a vision for the New England landscape. Harvard Forest, Harvard University, Petersham

Gibbs JP, Faaborg J (1990) Estimating the viability of Ovenbird and Kentucky warbler populations in forest fragments. Conserv Biol 4:193-196

Gladwell M (2000) The tipping point: how little things can make a big difference. Back Bay Books, Boston

Hansen AJ, Knight RL, Marzluff JM, Powell S, Brown K, Gude PH, Jones K (2005) Effects of exurban development on biodiversity: patterns, mechanisms, and research needs. Ecol Appl 15:1893-1905 
Haslem A, Bennett AF (2008) Birds in agricultural mosaics: the influence of landscape pattern and countryside heterogeneity. Ecol Appl 18:185-196

Johnson CJ, Boyce MS, Case RL, Cluff HD, Gau RJ, Gunn A, Mulders R (2005) Cumulative effects of human developments on arctic wildlife. Wildl Monogr 160:1-36

Lepczyk C, Wunnicke A, Radeloff V, Flather C, Pidgeon A, Hammer R (2013) Using housing growth to estimate habitat change: detecting Ovenbird response in a rapidly growing New England State. Urban Ecosyst 16:499-510

MacKenzie D, Bailey L (2004) Assessing the fit of site-occupancy models. J Agric Biol Environ Stat 9:300-318

MacKenzie D, Nichols JD, Royle JA, Pollock KH, Bailey LL, Hines JE (2006) Occupancy estimation and modeling. Academic Press, Burlington

Martin J, Chamaille-Jammes S, Nichols JD, Fritz H, Hines JE, Fonnesbeck CJ, MacKenzie D, Bailey LL (2010) Simultaneous modeling of habitat suitability, occupancy, and relative abundance: African elephants in Zimbabwe. Ecol Appl 20:1173-1182

McGowan KJ, Corwin K (2008) The second atlas of breeding birds in New York State. Cornell University Press, Ithaca

Morimoto DC, Frankel MA, Hersek M, Wasserman FE (2012) Forest fragmentation effects on ovenbird populations in the urban region of eastern Massachusetts, USA. Urban Habitats 7 http://www.urbanhabitats.org/v07n01/ forestfragmentation_full.html

Multi-Resolution Land Characteristics Consortium (2001) National Land Cover Database 2001. U.S. Geological Survey, MRLC Project, Sioux Falls, South Dakota. Available from www.mrlc.gov

New York State Department of Environmental Conservation (2015) New York State Wildlife Action Plan. 2015. New York State Department of Environmental Conservation. Albany, NY. http://www.dec.ny.gov/docs/wildlife_pdf/ swapfinaldraft2015.pdf

Niskanen S, Ostergard PRJ (2003) Cliquer User's Guide, Version 1.0. Communications Laboratory, Helsinki University of Technology

Nowak D, Walton JT (2005) Projected urban growth (20002050) and its estimated impact on the U.S. forest resource. J For 103:383-389

Ortega YK, Capen DE (1999) Effects of forest roads on habitat quality for ovenbirds in a forested landscape. Auk 116:937-946

Petrie MJ, Brasher MG, Soulliere GJ, Tirpak JM, Pool DB, Reker RR (2011) Guidelines for establishing Joint Venture waterfowl population abundance objectives. North American Waterfowl Management Plan Science Support Team Technical Report No. 2011-1, p 36

Pidgeon AM, Radeloff VC, Flather CH, Lepczyk CA, Clayton MK, Hawbaker TJ, Hammer RB (2007) Associations of forest bird species richness with housing and landscape patterns across the USA. Ecol Appl 17:1989-2010

Pinheiro J, Bates D, DebRoy S, Sarkar D, R Core Team (2017) nlme: Linear and Nonlinear Mixed Effects Models. R package version 3.1-131, https://CRAN.R-project.org/ package $=$ nlme

Porneluzi P, Van Horn MA, Donovan TM (2011) Ovenbird (Seiurus aurocapilla).in A. Poole, editor. The birds of
North America online. Cornell Lab of Ornithology, Ithaca, NY

R Core Team (2017) A language and environment for statistical computing. R Foundation for Statistical Computing, Vienna, Austria. http://www.R-project.org/

Radeloff VC, Hammer RB, Stewart SI (2005a) Rural and suburban sprawl in the US Midwest from 1940 to 2000 and its relation to forest fragmentation. Conserv Biol 19:793-805

Radeloff VC, Hammer RB, Stewart SI, Fried JS, Holcomb SS, McKeefry JF (2005b) The wildland-urban interface in the United States. Ecol Appl 15:799-805

Rasker R, Hansen A (2000) Natural amenities and population growth in the Greater Yellowstone region. Hum Ecol Rev 7:30-40

Robinson SK, Thompson FR, Donovan TM, Whitehead DR, Faaborg J (1995) Regional forest fragmentation and the nesting success of migratory birds. Science 267:1987-1990

Rosenberg KV, Blancher PJ (2005) Setting numerical populaiton objectives for priority landbird species. USDA Forest Service Gen Techn Rep. PSW-GTR-191

Schiller A, Hunsaker CT, Kane MA, Wolfe AK, Dale VH, Suter GW, Russell CS, Pion G, Jensen MH, Konar (VC) (2001) Communicating ecological indicators to decision makers and the public. Conservation Ecology 5(1): 19. http://www. consecol.org/vol5/iss1/art19/

Schwenk WS, Donovan TM (2011) A multi-species framework for landscape conservation planning. Conserv Biol 25:1010-1021

Scott JM, Heglund PJ, Morrison ML (eds) (2002) Predicting species occurrences: issues of accuracy and scale. Island Press, Washington, DC

Smith TM, Shugart HH (1987) Territory size variation in the Ovenbird: the role of habitat structure. Ecology 68:695-704

Stein SM, McRoberts RE, Alig RJ, Nelson MD, Theobald DM, Eley M, Dechter M, Carr M (2005) Forests on the edge: housing development on America's private forests.in F. S. U.S. Department of Agriculture, Pacific Northwest Research Station, editor., Portland, OR

Sushinsky JR, Rhodes JR, Possingham HP, Gill TK, Fuller RA (2012) How should we grow cities to minimize their biodiversity impacts? Glob Change Biol. doi:10.1111/gcb. 12055

Theobald DM (2001) Land-use dynamics beyond the American urban fringe. Geogr Rev 91:544-564

Theobald DM (2003) Targeting conservation action through assessment of protection and exurban threats. Conserv Biol 17:1624-1637

Theobald DM (2005) Landscape patterns of exurban growth in the USA from 1980 to 2020. Ecol Soc 10:32

Theobald DM, Miller JR, Hobbs NT (1997) Estimating the cumulative effects of development on wildlife habitat. Landsc Urban Plann 39:25-36

Thompson J, Lambert KF, Foster D, Blumstein M, Broadbent E, Zambrano AA (2014) Changes to the land: four scenarios for the future of the Massachusetts landscape. Harvard Forest, Harvard University, Petersham

Tittler R, Fahrig L, Villard MA (2006) Evidence of large-scale source-sink dynamics and long-distance dispersal among Wood Thrush populations. Ecology 87:3029-3036 
Turner MG, Gardner RH, O’Neill RV (2001) Landscape ecology in theory and practice: pattern and process. Springer, New York

Tyrrell M, Hall MHP, Sampson RN (2004) Dynamic models of land use change in Northeastern USA: developing tools, techniques, and talents for effective conservation action. GISF Res Pap 003:82

U.S. Census Bureau (2005) Ranking of census 2000 and projected 2030 state population and change: 2000 to 2030. Population Division

Vermont Forum on Sprawl (1999) Economic, social, and land use trends related to sprawl in Vermont. Burlington
Vermont Wildlife Action Plan Team (2015) Vermont Wildlife Action Plan 2015. Vermont Fish \& Wildlife Department. Montpelier, VT. http://www.vtfishandwildlife.com

Wilsey CB, Lawler JJ, Cimprich D, Schumaker NH (2014) Dependence of the endangered black-capped vireo on sustained cowbird management. Conser Biol 28:561-571

With KA, Schrott GR, King AW (2006) The implications of metalandscape connectivity for populaiton viability in migratory songbirds. Landscape Ecol 21:157-167 